\title{
El reclamo de Enriqueta Zuloaga como herramienta de aproximación al estudio del rol del Departamento Topográfico mendocino en el gobierno del territorio (1867)
}

Lucía Cortez*

Fecha de Recepción: 15 de julio de 2021

Fecha de Aceptación: 7 de octubre de 2021

DOI: https://doi.org/10.46553/RGES.57.2021.p.62-80

\begin{abstract}
Resumen
En abril de 1867 una vecina de la Ciudad de Mendoza, Enriqueta Zuloaga, envió una carta al gobernador de Mendoza cuestionando la forma en la que José Galigniana, agrimensor y director del Departamento Topográfico, había realizado la delineación de su terreno solicitando la intervención de diversas autoridades con el fin de que su conflicto fuera resuelto. Este trabajo pretende ser una aproximación al rol de esa oficina y de los agrimensores en el gobierno del territorio provincial, de su relación con los vecinos/as y con otros agentes y agencias del Estado provincial. Para ello, se siguen dos ejes teóricos: el primero, vinculado al conocimiento de la historia de Mendoza en la década de 1860 y de la realidad política, social y económica de la provincia, junto con la relevancia que tenía el Departamento Topográfico dentro de la administración local, y el segundo, se relaciona con el campo de estudio del Estado y sus agencias en cuyo marco se abordará la conformación de esta oficina pública de Mendoza.
\end{abstract}

Palabras clave: Agencias estatales; Departamento Topográfico; Mendoza.

\begin{abstract}
In April 1867 a neighbor of the City of Mendoza, Enriqueta Zuloaga, sent a letter to the governor of Mendoza questioning the way in which José Galigniana, surveyor and director of the Topographic Department, had made the delineation of her land requesting the intervention of various authorities in order for their conflict to be resolved. This work aims to be an approximation to the role of that office and of the surveyors in the government of the provincial territory, of their relationship with the neighbors and with other agents and agencies of the provincial State. For this, two theoretical axes are followed: the first, linked to the knowledge of the history of Mendoza in the $1860 \mathrm{~s}$ and of the political, social and economic reality of the province, together with the relevance that the Topographic Department had within the local administration, and the second, is related to the field of study of the State and its agencies within which framework the formation of this public office in Mendoza will be addressed.
\end{abstract}

Keywords: State agencies; Topographic Department; Mendoza.

\section{Introducción}

El 4 de abril de 1867 una vecina de la Ciudad de Mendoza, Doña Enriqueta Zuloaga,

\footnotetext{
* Universidad Nacional de Cuyo - Instituto Multidisciplinario de Estudios Sociales Contemporáneos (IMESC) Instituto de Estudios Históricos, Económicos, Sociales e Internacionales (IDEHESI), CONICET. lulicortez_11@hotmail.com
} 
envió una carta al gobernador de la provincia de Mendoza cuestionando la forma en la que José Galigniana, agrimensor y miembro de la oficina estatal, había realizado la delineación de su terreno argumentando no estar conforme en tanto se veía afectada en la superficie que ésta establecía y, al mismo tiempo, complicaba la continuidad de la construcción que ella se había dispuesto a iniciar un tiempo atrás. En el documento también solicitaba la pronta intervención de las autoridades del Departamento Topográfico y de otras reparticiones estatales que pudiesen estar afectadas en la materia, con el fin de que su conflicto fuera resuelto.

El estudio de este caso en particular pretende ser un observatorio para, en primer lugar, el conocimiento del rol del Departamento Topográfico y los agrimensores que lo componían en la gestión del territorio y, en segundo lugar, a la relación que ésta tenía con los vecinos/as y con otros agentes y agencias del Estado provincial. ${ }^{1}$ Para ello, se articula el análisis a partir de dos ejes que buscan ser las vías de acceso al estudio del caso: el primero de ellos está vinculado al contexto mendocino durante la década de 1860 para-comprender cuál era la trama política, social y económica de la provincia, junto con la relevancia que tenía el Departamento Topográfico dentro de la administración local, ${ }^{2}$ mientras que el segundo se relaciona con el estudio del Estado y sus agencias a partir de recientes investigaciones que han configurado y enriquecido este campo historiográfico. ${ }^{3}$ Cabe destacar, que el análisis de este

\footnotetext{
${ }^{1}$ Este trabajo se enmarca dentro de una beca doctoral de CONICET (2020-2025), cuyo plan de investigación lleva por título "Trayectorias de instituciones y gestores vinculados al proceso de apropiación territorial del Estado provincial en Mendoza, fines del siglo XIX y comienzos del siglo XX". Cabe marcar que la beca se otorgó en el marco del Proyecto de Unidad Ejecutora de CONICET Convocatoria 2018 "El Estado Argentino y sus gestores: trayectorias, identidades y disrupciones, 1852/3-2010. De lo disyunto a lo complejo" (Responsable científico: Dra. Beatriz Figallo. Código 22920180100003 CO. Periodo 2019-2023).

${ }^{2}$ Recientes investigaciones han aportado ya a la reconstrucción del proceso histórico local post Caseros a través de diversos aspectos. Entre las más relevantes, Beatriz Bragoni, "Cuyo después de Pavón: consenso, rebelión y orden político, 1861-1874”, en Un nuevo orden político. Provincias y Estado Nacional 1852-1880, coordinado por Beatriz Bragoni y Eduardo Míguez, (Buenos Aires: Biblos, 2010), 20-60; "Recuperación y desigualdad económica en el interior rural argentino del siglo XIX. Un examen sobre la composición y distribución de la riqueza en la campaña de Mendoza a través de sus fuentes fiscales (1866)". América Latina en la historia económica 25 (2011): 211-244; Fucili Eliana, Los forjadores del poder. Retratos de dirigentes territoriales de Mendoza en la segunda mitad del siglo XIX, (Mendoza: Ediunc, 2019); Gabriela García Garino, El más alto poder: Legislatura y cultura política en el proceso de construcción del Estado provincial de Mendoza, 18521880, (Mendoza: Tesis doctoral presentada en el Doctorado en Historia, Universidad de Buenos Aires, sin editar, 2016); Eugenia Molina, Del oficio al cargo público. El caso de la creación del Departamento Topográfico, Mendoza (1850-1860), (La Falda: VII Jornadas Nacionales de Historia Social, sin editar, 2018); “Agrimensores, gobierno y derecho en prácticas institucionales de ordenamiento territorial. Jurisdicción de Mendoza, 18501860". Revista Historia y Justicia, 13 (2019): sin paginación.

${ }^{3}$ Ernesto Bohoslavsky y Germán Soprano, Un Estado con rostro humano. Funcionarios e instituciones estatales de Argentina (de 1880 a la actualidad), (Buenos Aires: Universidad Nacional General Sarmiento - Prometeo, 2010). Además: Ernesto Bohoslavsky, "El rostro humano de la historia del Estado". Estudios Sociales de Estado, 1 (2015): 239-247; Sergio Morressi y Gabriel Vonmaro, Saber lo que se hace. Expertos y política en Argentina, (Buenos Aires: Universidad General Sarmiento - Prometeo: 2011); Mariano Ben Plotkin y Eduardo Zimmermann, Las prácticas del Estado. Política, sociedad y elites estatales en la Argentina del siglo XX, (Buenos Aires: Edhasa, 2012); Los saberes del Estado, (Buenos Aires: Edhasa, 2012); Germán Soprano y Silvia Di Liscia, Burocracias estatales: problemas, reformas, enfoques y etudios de caso en la Argentina: entre fines
} 
caso en profundidad será acompañado de la presentación de algunos documentos que, previamente a que Enriqueta hiciera su reclamo, fueron elaborados por otros vecinos para presentar similares demandas para que las autoridades atendieran.

Con este análisis micro se busca aportar a un estudio del Estado en tanto relación social, personalizado en sus agencias (Departamento Topográfico, Inspección de Irrigación, Catastro) y sus sujetos (agrimensores, ingenieros, arquitectos), los cuales tuvieron trayectorias particulares y fueron portadores de un saber que legitimó su intervención en el territorio y en el control social de una población determinada. No obstante, es claro que se está hablando de un Estado aún en construcción, es decir, con una burocracia incipiente en un lugar y tiempo específico: Mendoza a fines del siglo XIX y principios del siglo XX. Un Estado que aparece desacoplado, desintegrado y, por lo tanto, muy lejos de mostrarse como un aparato inabordable. Se busca, así, estudiar un Estado descentrado, desde los márgenes, conociendo el proceso de institucionalización que trascendió los límites arbitrariamente auto-impuestos para tal investigación, pero como un esfuerzo por abandonar toda visión teleológica que solo sirva para impedir atender a las especificidades y la historicidad de la cuestión.

El estudio tanto de los agentes estatales como de los expertos se ha convertido en un núcleo de investigación recurrente en los últimos años. ${ }^{4}$ La mayoría de estos trabajos se centra en el estudio del "vínculo íntimamente constitutivo que se ha dado entre ciertas formas de conocimiento y su institucionalización". 5 Es decir, de aquellos saberes especializados y-de sus portadores de los cuales el Estado -en su génesis, consolidación y posteriores transformaciones- se ha valido para alcanzar distintas modalidades de intervención en el territorio y en las poblaciones cuyo control reivindica. Se trata de indagar en los vínculos entre el campo del saber y el campo del poder, en los que la influencia de la teoría de Pierre Bourdieu se torna evidente. ${ }^{6}$ En otras palabras, no solo reconocer, sino también, analizar el rol social y político de los "expertos".

En ese sentido, la investigación que aquí se presenta está compuesta de cuatro apartados a las que le siguen una serie de consideraciones finales y posibles interrogantes para encarar futuras líneas de indagación. El primero de ellos está destinado a presentar las notas principales de la realidad política, social y económica de Mendoza en la década de 1860 a

del siglo XIX y XX, (Rosario: Prohistoria, 2017); Guillermo O’Donnell, Apuntes para una teoría del Estado (Buenos Aires: CLACSO, 1977).

${ }^{4}$ Morresi y Vonmaro, Saber lo que se hace; Plotkin y Zimmermann, Los saberes del Estado; Plotkin y Zimmermann, Las prácticas del Estado; Soprano y Di Liscia, Burocracias estatales.

${ }^{5}$ Plotkin y Zimmermann, Los saberes del Estado, 11.

${ }^{6}$ Pierre Bourdieu, Sobre el Estado. Cursos en el College de France (1989-1992), (Barcelona: Anagrama, 2014); Pierre Bourdieu, Intelectuales, política y poder, (Buenos Aires: Eudeba, 1999). 
partir de un recorrido por los estudios realizados desde distintas perspectivas historiográficas con el objeto de contextualizar históricamente el caso que aquí se presenta. El segundo apartado realiza un acercamiento a las características del Departamento Topográfico, para definir qué funciones cumplía desde su creación, los miembros que lo componían, los campos de acción que desplegaba, desde una mirada que recupera el Estado de la cuestión actual respecto del estudio de las agencias y agentes estatales y sus saberes especializados. En el tercer apartado, se presentará una descripción detallada de una serie de fuentes originales con el objetivo de conocer en profundidad, por un lado, cuáles eran los canales habilitados para que, ciudadanos presentaran un conflicto vinculado al accionar de miembros del Departamento y, por el otro, si existían efectivamente procedimientos aceitados para canalizar esas demandas y el modo en el que éstas se resolvían, prestando especial atención a las distintas autoridades que intervinieran en dicho proceso. Por último, se presentarán una serie de documentos que permiten contextualizar el reclamo de Enriqueta Zuloaga y reflexionar acerca de la excepcionalidad del mismo.

Se trata de un conjunto de documentos preservados por el Archivo Histórico de la Provincia de Mendoza (A.G.P.M.) y ubicado en la Sección Independiente, en la carpeta $n^{\circ} 34$, una de las dos destinadas a los documentos vinculados al Departamento Topográfico. En los mismos tienen lugar una multiplicidad de interacciones, reclamos e informes entre una ciudadana y agentes del Estado provincial que buscaron dar solución al conflicto que los originaban en cada uno de los casos.

\section{Mendoza en la década de 1860, una aproximación desde la historiografía local}

El estudio de la historia local a partir de 1861 ha sido un tema visitado por diversos autores y autoras que, desde distintas perspectivas, han logrado construir un corpus historiográfico creciente sobre el período. Por una parte, en los historiadores inscritos en lo que podría denominarse tradición liberal o quienes se ubican más cercanos al revisionismo, ${ }^{7}$ el denominador común ha sido la presentación de ciertas claves explicativas: el vínculo directo con el avance del liberalismo porteño, la antinomia "federal"/"liberal", la red vincular de un grupo reducido de familias que fue ocupando los cargos disponibles en el gobierno

\footnotetext{
${ }^{7}$ Edmundo Correas, "Historia de Mendoza", en Historia Argentina contemporánea 1862-1930. Historia de las Provincias y sus pueblos. Academia Nacional de la Historia, vol. IV, (Buenos Aires: El Ateneo:1967), 459-502; José Luis Masini Calderón, Mendoza hace cien años. Historia de la provincia durante la presidencia de Mitre, (Mendoza: Theoría, 1967); Pedro Santos Martínez, Historia de Mendoza, (Buenos Aires: Plus Ultra, 1979) y Jorge Scalvini, Historia de Mendoza, (Mendoza: Spadoni, 1965).
} 
provincial. Mientras, otra serie de trabajos partió de la Historia del Derecho y las Instituciones como vía de acceso a la comprensión de la vida política local a partir del marco normativo que la regulaba y su transformación marcada por diversos contextos ideológicos. ${ }^{8}$

Sin embargo, la renovación historiográfica de finales del siglo pasado provocó que a partir de hace un par de lustros emergieran estudios que fueran a tono con esa transformación teórica y metodológica. Desde la nueva Historia política se aportaron reflexiones que apuntaron a repensar las lógicas locales de organización del Estado, la cultura política y los elencos que ocuparon lugares cruciales en la administración mendocina, complejizando los paradigmas explicativos del proceso de consolidación nacional desde una mirada que ha buscado reivindicar las experiencias de las provincias. ${ }^{9}$ En efecto, esta historiografía ha explicado cómo, durante este periodo, Mendoza asistió al proceso de construcción y posterior consolidación de un aparato estatal de dimensión provincial, sustentado en la Constitución provincial de 1854, caracterizada por notas claras de un constitucionalismo liberal en tanto remitía a la soberanía popular, a la división de poderes y a la existencia de derechos y garantías individuales, pero al mismo tiempo, tenía ciertos rasgos conservadores, especialmente en la estipulación de quiénes podían elegir y ser elegidos. ${ }^{10}$ El ritmo de ese proceso habría estado marcado por una élite que si bien, en términos generales, se caracterizaba por su cohesión, no dejaba de fraccionarse ante situaciones coyunturales como los escenarios electorales o el tratamiento de una ley particular. De esta manera, la cultura política se organizaba en torno a un "consenso liberal"," considerándose que no puede entenderse si se la reduce al "producto de un puñado de parientes y amigos que monopolizaban los cargos públicos". 12 Asimismo, tal como ha demostrado Eliana Fucili, se implementaron reformas y dispositivos territoriales con el objeto de legitimar el nuevo orden político provincial y nacional. ${ }^{13}$

Al mismo tiempo, desde la perspectiva de una historia económica regional, los

\footnotetext{
${ }^{8}$ Cristina Seghesso, Historia Constitucional de Mendoza, (Mendoza: Instituto Argentino de Estudios Constitucionales y Políticos, 1997); Inés Sanjurjo, La Organización político-administrativa en la campaña mendocina en el tránsito del antiguo régimen al orden liberal, (Buenos Aires: Instituto de Investigaciones de Historia del Derecho, 2004); Dardo Pérez Guilhou, 1854. Dos proyectos político constitucionales, Buenos Aires y Mendoza, (Mendoza: Instituto Argentino de Estudios Constitucionales y Políticos - Ex Libris, 2005) y Carlos Egües, Historia Constitucional de Mendoza: los procesos de reforma, (Mendoza: Ediunc, 2008).

9 Bragoni, "Cuyo después de Pavón”; Bragoni, "Recuperación y desigualdad económica"; García Garino, El más alto poder y Fuscili, Los forjadores del poder.

${ }^{10}$ García Garino, El más alto poder.

${ }^{11}$ García Garino, El más alto poder, 152-156.

12 Bragoni, "Cuyo después de Pavón", 60.

${ }^{13}$ Fuscili, Los forjadores del poder, 16.
} 
trabajos de Rodolfo Richard Jorba ${ }^{14}$ han aportado una lúcida visión acerca del sistema productivo de la provincia y las relaciones sociales que, a partir de él, se articularon desde mediados del siglo XIX hasta la segunda década del siglo siguiente. En el período en cuestión la provincia de Mendoza pasó de un modelo productivo basado en la ganadería comercial con agricultura subordinada (1850-1880) a un modelo agroindustrial basado en la vitivinicultura, proceso que estuvo signado por un afianzamiento del capitalismo y el traspaso de la influencia de una oligarquía modernizadora que habría dominado el poder político y económico hasta que este último, a partir de la década de 1870, habría pasado a manos de una burguesía de origen inmigratorio. ${ }^{15}$ Igual de valioso ha sido su análisis de la composición social de Mendoza en esta época, la cual no solo creció de manera contundente y se recuperó del golpe que significó el terremoto de 1861 en tanto que de la población urbana de aproximadamente 8000 habitantes, murieron alrededor de 5000, sino que también se caracterizó por presentar grupos bien diferenciados que, a pesar de los movimientos migratorios y la movilidad social consecuencia de estos, se mantuvo en el período. ${ }^{16}$ Como aclara Gabriela García Garino, en la cúspide de la pirámide demográfica se encontraba "un grupo dominante minoritario asentado sobre la propiedad de la tierra y el acceso al agua -dos pilares de las principales actividades económicas-, de vínculos comerciales que podían ofrecer información y de un fuerte capital social, cultural y relacional que le posibilitaba el acceso al poder". ${ }^{17}$ Mientras que el resto de la población se dividía entre el sector medio, representado por pequeños comerciantes, propietarios y artesanos, y la gran mayoría que se dedicaba a tareas de escasa calificación vinculadas a los servicios, ganadería, agricultura y otras actividades extractivas.

Por otro lado, los trabajos que provienen desde la historia social de la justicia y el gobierno han representado una contribución relevante para repensar el rol de determinados agentes estatales en la construcción de un poder estatal legítimo y los vínculos de éste con la población que intentaba gobernar a través de un elenco de sujetos detentores de un saber más o menos especializado. ${ }^{18}$ Asimismo, una serie de trabajos que no parten desde la historia como disciplina inicial pero sí plantean un diálogo estimulante con la problemática que se

\footnotetext{
${ }^{14}$ Rodolfo Richard Jorba, Poder, economía y espacio en Mendoza, 1850-1900, (Mendoza: Facultad de Filosofía y Letras - Universidad Nacional de Cuyo, 1998) y Rodolfo Richard Jorba, Empresarios ricos, trabajadores pobres. Vitivinicultura y desarrollo capitalista en Mendoza (1870-1918), (Rosario: Prohistoria, 2010).

${ }^{15}$ Richard Jorba, Empresarios ricos, 20-26.

${ }^{16}$ Richard Jorba, Empresarios ricos, 78-79.

${ }^{17}$ García Garino, El más alto poder, 69.

18 Molina, "Del oficio al cargo público"; Molina, "Agrimensores, gobierno y derecho"; Silvia Cirvini, La estructura profesional y técnica en la construcción de Mendoza (I): los agrimensores, (Resistencia: Instituto Argentino de Investigaciones en Historia de la Arquitectura y el Urbanismo, 1989) y Silvia Cirvini, "Mendoza, la arquitectura de la reconstrucción posterremoto". Revista América, 108 (1986): 171-188.
} 
propone estudiar, ha fortalecido los vínculos con la Antropología conectados con la demanda del reconocimiento de propiedad de la tierra por parte de pueblos originarios junto con los conflictos que emergen del lazo de estas con el Estado en configuración. ${ }^{19}$ Junto con ello, otra de las líneas ha sido la surgida de la relación entre la Geografía y la Historia, de la Historia ambiental y, también de la Ecología política, cuyos aportes ha resultado clave para problematizar la espacialidad, la gestión de recursos - fundamentalmente el agua- y las redes sociales que se articulan en torno a ellos. ${ }^{20}$

Puntualmente el año 1867 formó parte de una década convulsionada en la historia de Mendoza, signada por una serie de acontecimientos que tuvieron gran impacto en la coyuntura de ese momento y generaron algunas transformaciones en el mediano y largo plazo. Por un lado, el año 1861 no solo fue un año crucial en la historia de construcción del Estado nacional en tanto momento de la Batalla de Pavón que marcó el inicio de la organización nacional bajo la hegemonía mitrista, ${ }^{21}$ sino que aún más relevante a los fines de este estudio, a nivel local un terremoto destruyó por completo a la ciudad y diezmó a un tercio de la población urbana, como ya se refirió. En este sentido, las consecuencias de ese cataclismo a nivel infraestructural, demográfico y económico fueron de tal envergadura que implicó, entre otras cosas, el traslado de la ciudad. ${ }^{22}$

Otras de los aspectos centrales de ese período es que, conforme al proceso de organización del Estado nacional intentaba avanzar, Mendoza asistió a diversas rebeliones que fueron marcando el ritmo de la estabilización - o no- del orden político. Al margen de los conflictos que emergían generalmente en las coyunturas electorales, la elite gobernante tuvo que enfrentar aquellos que estaban más vinculados a la persistencia de la influencia de una serie de liderazgos sociales y territoriales que trascendían las fronteras provinciales, como lo fueron tanto el levantamiento de 1863 liderado por Francisco Clavero, quien acompañado de

\footnotetext{
${ }^{19}$ Diego Escolar, "Huarpes Archives in the Argentine Desert: Ingenious claims and State Construction in Ninteenth-Century Mendoza". Hispanic American Historical Review, 93, 3 (2013): 451-486.

${ }^{20}$ María del Rosario Prieto y Elena Abraham, Caminos y comercio como factores de cambio ambiental en las planicies áridas de Mendoza (Argentina) entre los siglos XVII y XIX, (Tucumán: Trabajo presentado en las Jornadas de Historia Económica, 2000); María del Rosario Prieto, Elena Abraham y Patricia Dussel, "Transformaciones de un ecosistema palustre. La gran ciénaga de Bermejo-Mendoza, siglos XVIII y XIX". Multequina, num. 17 (2008), 147-164; Facundo Martín, Facundo Rojas y Leticia Saldi, "Domar el agua para gobernar. Concepciones sociopolíticas sobre la naturaleza de la sociedad en contextos de consolidación del Estado Provincial mendocino hacia finales del siglo XIX y principios del XX”. Anuario del Centro de Estudios Históricos "Prof. Carlos S. A. Segreti", año 10, num. 10 (2010): 159-186.

${ }^{21}$ Hilda Sábato, Historia de la Argentina, 1852-1890, (Buenos Aires: Siglo XXI, 2012); Hilda Sábato, "Milicias, ciudadanía y producción: el ocaso de una tradición política”, en Un nuevo orden político. Provincias y Estado Nacional 1852-1880, coordinado por Beatriz Bragoni y Eduardo Míguez, (Buenos Aires: Biblos, 2010), 227 244.; Hilda Sábato y Alberto Lettieri, La vida política en la Argentina del siglo XIX: armas, votos y voces, (Buenos Aires: Fondo de Cultura Económica, 2003; Beatriz Bragoni y Paula Alonso, El sistema federal argentino. Debates y coyunturas (1860-1910), (Buenos Aires: Edhasa, 2015).

${ }^{22}$ Cirvini, "Mendoza, la arquitectura"; Cirvini, La estructura profesional y técnica.
} 
treinta personas asaltó y logró deponer al subdelegado de San Carlos, como la "Revolución de los Colorados" de 1866 motivada por la Guerra del Paraguay, que logró deponer al gobernador recientemente electo, Melitón Arroyo, y formar un gobierno propio que se mantuvo entre los meses de noviembre de 1866 y abril de $1867 .^{23}$

Toda esta contextualización cobra relevancia en este estudio en tanto afectó los procesos de efectiva institucionalización de algunas de las oficinas y agencias estatales aquí estudiadas. Conocer estos acontecimientos podrían contribuir a una comprensión del complejo cuadro de circunstancias en el cual se inserta el objeto de este estudio.

\section{El Departamento Topográfico, oficina estatal dedicada al gobierno del territorio}

Para poder encarar un estudio que haga hincapié en el Departamento Topográfico mendocino y en los agrimensores que dentro de su órbita aplicaron sus saberes, ha sido necesario recuperar una serie de trabajos que se hayan interesado por las oficinas y burocracias estatales abocadas al registro catastral de la jurisdicción en la que éstas operaban, el cual se ha convertido en un campo de indagación que ha proliferado en la historiografía latinoamericana y argentina en los últimos años. Ésta ha advertido que, a partir de mediados del siglo XIX, durante el proceso de organización y consolidación de los Estados nacionales, se ha hecho necesario para los gobiernos conocer el territorio en el que actúan ya que, el registro administrativo de la tierra, lo dotaba de un saber funcional para transformar e incidir en el territorio. Las vías para abordar este proceso mediante el cual el Estado adquiere información territorial y proyecta a partir de ella han sido múltiples, pudiéndose identificar dos que se han desarrollado articuladas entre sí. Por un lado, aquella que ha focalizado en el proceso de formación de oficinas y agencias estatales destinadas al registro catastral, su origen y evolución y, por el otro, una línea de investigación que se ha interesado en los agrimensores, la institucionalización de sus saberes, sus trayectorias y formación. ${ }^{24}$

\footnotetext{
${ }^{23}$ Bragoni, “Cuyo después de pavón”, 37-42 y García Garino, El más alto poder, 93.

${ }^{24}$ La compilación de Juan Carlos Garavaglia y Pierre Gautreau reunió una serie de trabajos sobre el área rioplatense y algunos casos del espacio hispanomaericano que ha resultado de referencia obligada para investigación posteriores, Mensurar la tierra, controlar el territorio. América Latina, s. XVIII y XIX, (Rosario: Prohistoria, 2011); Valeria D'Agostino, Estado, instituciones y funcionarios: el Departamento Topográfico bonaerense en la segunda mitad del siglo XX, (Bariloche: trabajo presentado en el III Congreso Latinoamericano de Historia Económica - XVIII jornadas de Historia Económica, 2012); Mariana Canedo, "El restablecimiento del Departamento Topográfico de Buenos Aires. Política y gestión de un proyecto en consenso". Andes. Antropología e Historia, 25 (2014): sin paginación; Melisa Pesoa Marcilla, "Conocer, medir y dibujar el territorio. Orígenes y etapa formativa del Departamento Topográfico de Buenos Aires (1824-1851). Boletín Americanista, 75 (2017): 153-172; Raquel Bressan, "Registrar, ordenar, planificar. El Departamento Topográfico de Entre Ríos (1871-1883). Revista de Estudios Sociales Contemporáneos, 17 (2017): 36-52;
} 
En este sentido, esta línea de indagaciones ha mostrado cómo las Comisiones y los Departamentos Topográficos provinciales tuvieron tareas comunes: eran los encargados de todas las mensuras de tierras privadas y públicas; tenían la responsabilidad de examinar y dirigir a los agrimensores que actuaban en sus jurisdicciones; se encargaban del ordenamiento territorial, como también de todas las tareas vinculadas a la irrigación y al diseño y gestión del espacio público. Otra de las cuestiones que aparecen como una tendencia coincidente es que, a medida que fue pasando el tiempo, se asistió a una especialización cada vez mayor en las tareas, generando modificaciones en su organigrama y diversificaciones institucionales. Así, en Córdoba, el Departamento Topográfico se dividió en la sección de Geodesia, Obras Públicas e Irrigación ${ }^{25}$ y en Buenos Aires terminó siendo absorbido por el Ministerio de Obras Públicas. ${ }^{26}$

La línea de indagación vinculada con los elencos técnicos de esas oficinas estatales se ha enfocado en las personas que contaban con el saber requerido para las tareas relativas al conocimiento del territorio, en principio, los agrimensores. Si bien es cierto que también ingenieros y, posteriormente, arquitectos tuvieron su incidencia, priorizamos las trayectorias de los agrimensores ya que eran "detentores de un capital cultural, es decir, de un capital socialmente sancionado y que para ese momento histórico se revistió de un carácter vigente: la mensura, delineación y representación gráfica de la realidad". ${ }^{27}$ Tal como sucedía en Mendoza hacia 1845, donde "este saber conectado con la apertura de calles, acequias y desagües parece haberse identificado ya más claramente con el término agrimensor". ${ }^{28}$

Según han evidenciado estos estudios, las Comisiones Topográficas y Departamentos Topográficos tenían una organización jerárquica y generalmente un elenco técnico estable, la misma gente en distintos cargos con ciertas lógicas internas de ascenso o permanencia. ${ }^{29} \mathrm{En}$ una etapa inicial, la mayoría de los agrimensores habrían provenido del extranjero, hasta

Malena Mazzitelli Mastricchio, "Los jueces de la medida, el rol de los agrimensores entrerrianos en el Departamento Topográfico de Entre Ríos (1849-1871)". Revista Brasileira de História da Ciencia, 11 (2018): 720; Carlos Page, "Formación y desarrollo de las reparticiones oficiales de agrimensura, ingeniería y arquitectura. Profesionales con actuación en Córdoba 1850-1900”. Revista de la Junta Provincial de Historia, n²2 (2005): 141-160; Ana Sofía Maizón, "Construyendo el territorio: contexto internacional, prácticas y dinámicas de la agrimensura en la provincia de Córdoba, Argentina. Fines del siglo XIX”. Revista Brasileira de História da Ciencia, vol. 6, n 1 (2013): 89-105; Molina, "Del oficio al cargo público"; Molina, "Agrimensores, gobierno y derecho" y Lily Álvarez Correa, Catastro de propiedad en Chile: orígenes y evolución, (Barcelona: Universitat de Barcelona: 2014).

${ }^{25}$ Maizón, "Construyendo el territorio".

${ }^{26}$ Juan Carlos Garavaglia y Pierre Gatreau, "Inventando un nuevo saber estatal en el territorio: la definición de prácticas, comportamientos y agentes en las instituciones topográficas de Buenos Aires, 1824-1864", en Mensurar la tierra, controlar el territorio,63-96; D’Agostino, Estado, instituciones y funcionarios; Canedo, "El restablecimiento del Departamento Topográfico" y Pesoa Marcilla, "Conocer, medir y dibujar el territorio".

${ }^{27}$ Maizón, "Construyendo el territorio", 90.

${ }^{28}$ Molina, "Agrimensores, gobierno y derecho", 5.

${ }^{29}$ Canedo, "El restablecimiento del Departamento Topográfico". 
mediados del siglo XIX; así, en el caso chileno, habrían sido particularmente franceses. ${ }^{30}$ Esta ecuación cambiaría recién a finales de siglo XIX y principios del siglo XX cuando la "Academia Nacional de Ciencias" de Córdoba obtuviera el rango de facultad dentro de la Universidad en 1876 y habilitara el estudio y profesionalización. ${ }^{31}$ Hasta ese momento, Garavaglia y Gautreau plantean que, al menos en Buenos Aires, los agrimensores debían "probar" ante el Departamento Topográfico que contaban con ese capital cultural en el oficio. Esto explicaría que cada una de las oficinas estatales provinciales dispusiera de un reglamento que establecía cómo debía ser el proceso de habilitación de los agrimensores y, particularmente allí, se creara una Escuela Especial para homogeneizar los métodos y la cultura laboral, rindiendo los aspirantes un examen de conocimientos teóricos y luego cumpliendo un período de "adiestramiento" de salidas al campo con algún agrimensor ya habilitado. No obstante, otra de las cuestiones señaladas por la literatura atiende a la dimensión simbólica de su labor. Como ha mostrado Malena Mastricchio Mazzitelli, los agrimensores en tanto "jueces de la medida" tenían la responsabilidad, a través de sus actos, de generar el consenso social necesario para alcanzar la legitimación de la intervención material y simbólica territorial por parte del Estado. ${ }^{32}$

\section{El año 1867: tareas, proyectos y presupuestos}

El año 1867 se enmarca en un período de convulsión política y esta posiblemente sea la razón por la cual se explique que son escasos los documentos conservados en el Archivo General de la Provincia de Mendoza que refieran directamente al Departamento Topográfico o, al menos, a otro tipo de cuestiones que formen parte de su órbita. Esta oficina tiene anclaje en la década anterior, más puntualmente en 1853, año en el que, por medio de un decreto, se formaba la "Comisión Topográfica y de Estadística", a partir de la supuesta necesidad de una Departamento que dirigiera las obras públicas de la provincia. ${ }^{33}$

Según lo estipulado por ese decreto, la Comisión Topográfica debía abocarse, en términos generales, a todo lo relativo a límites y distribución de tierras públicas y particulares, a la delineación de calles y caminos, al levantamiento de planos y formación y a la indicación e inspección de las obras públicas y, puntualmente, al control y dirección de los

\footnotetext{
${ }^{30}$ Álvarez Correa, Catastro de propiedad.

${ }^{31}$ Page, "Formación y desarrollo".

32 Mazzitelli Mastricchio, "Los jueces de la medida", 13.

${ }^{33}$ Molina, "Agrimensores, gobierno y derecho", 7.
} 
agrimensores. ${ }^{34}$ En lo relativo a ello, a partir de 1853, se volvió requisito obligatorio que éstos presentaran en la oficina todos los planos confeccionados por ellos para que, luego de su examen y aprobación por parte de quien fuera director del Departamento, se registrara y archivara una copia de los mismos. Por último, se sumaban tareas más vinculadas a lo judicial en tanto que se planteaba la necesidad de "informar al Gobierno, Juzgados i Tribunales de Justicia sobre las mensuras practicadas i en las cuestiones que se susciten sobre propiedad territorial"35 como también se le adjudicaban todas aquellas "funciones del Tribunal Topográfico en los asuntos contenciosos i juicios de la facultad", ${ }^{36}$ es decir, eran los miembros de la Comisión los que debían intervenir y decidir en los conflictos que emergieran dentro de su órbita de acción y conocimiento, reconociéndoles de esa manera un saber especializado.

Volviendo al año 1867, en una comparación entre el recurso material que el gobierno provincial destinaba al Departamento Topográfico y el de otras oficinas del Estado local, este era escaso. Según la ley de presupuesto establecida para ese año, esta oficina estatal contó con 310 pesos, los cuales estaban destinados a cubrir el sueldo del "agrimensor de la ciudad", en ese momento José Galigniana, el cual constaba de 40 pesos mensuales, y un resto de 70 pesos anuales para otro tipo de gastos, ${ }^{37}$ mientras que, por ejemplo, para el Juzgado de Aguas se destinaron 1085 pesos. ${ }^{38}$ Sin embargo y más allá del escaso recurso material que el gobierno destinaba a esta oficina, lo cual deja en evidencia que no era ciertamente su prioridad, fueron dos los proyectos que se emprendieron.

El primero de ellos se trata del decreto sancionado en el mes de noviembre de 1867 por la legislatura de la provincia de Mendoza, mediante el cual se autorizó al Poder Ejecutivo "para contratar con el Agrimensor Julio Balloffet la formación del plano topográfico". ${ }^{39}$ De esta manera, este último se comprometía en los próximos cinco años y por la suma de "7000 pesos bolivianos" 40 a levantar un plano de la parte cultivada de la provincia, "deslindando con el sur por el río de Mendoza; en el norte por una línea recta pasando por el pozo del Borbollón; y tirada este-oeste desde la falda de los primeros cerrillos de la Cordillera hasta la orilla oeste del Río de Mendoza". ${ }^{41}$ El segundo proyecto radicaba en la formación de una

\footnotetext{
${ }^{34}$ Estas tareas y obligaciones están detalladas entre los artículos $2^{\circ}$ y $4^{\circ}$ del decreto de creación de la Comisión Topográfica. A.G.P.M. Sección Independiente. Registro oficial, mayo 1853. Pág. 2.

${ }^{35}$ A.G.P.M. Sección Independiente. Registro oficial, mayo 1853. Artículo $7^{\circ}$. Pág. 2.

${ }^{36}$ A.G.P.M. Sección Independiente. Registro oficial, mayo 1853. Artículo 1 . Pág. 2.

${ }^{37}$ A.G.P.M. Sección Independiente. Registro Oficial año 1867. Pág. 99.

${ }^{38}$ A.G.P.M. Sección Independiente. Registro Oficial año 1867. Pág. 97-107.

${ }^{39}$ A.G.P.M. Sección Independiente. Registro Oficial año 1867. Pág. 144.

${ }^{40}$ A.G.P.M. Sección Independiente. Registro Oficial año 1867. Pág. 143.

${ }^{41}$ A.G.P.M. Sección Independiente. Registro Oficial año 1867. Pág. 142.
} 
comisión por parte del agrimensor José Galigniana y los ciudadanos Melchor Villanueva y Antonio Guiñazú, con el objeto de evaluar si el subastador del Río, Ejido Videla, había cumplido o no con lo pactado en 1865 en torno a la construcción de un "canal zanjón". ${ }^{42}$

A pesar de no saber por ahora si efectivamente ambos proyectos se concretaron, lo relevante es que, tanto en uno como en otro, los agrimensores que los protagonizan están implicados en el caso que se describe a continuación.

\section{El caso de Enriqueta Zuloaga y el saber especializado como principio legitimador}

Enriqueta Zuloaga, una ciudadana y propietaria de la ciudad de Mendoza, el día 4 de abril de 1867 enviaba una carta al gobernador de la provincia de Mendoza cuestionando la delineación que de su terreno había realizado el agrimensor José Galigniana, entonces director del Departamento Topográfico. Cuando afirmamos que Enriqueta era propietaria, es importante destacar que, en la fuente consultada, no hay referencia al menos de manera explícita a normas constitucionales como tampoco figuran argumentos tradicionales que legitimen tal derecho de dominio. Es decir, la señora se presenta como legítima propietaria y no hay ningún tipo de sospecha o, incluso, verificación de que efectivamente lo sea.

En palabras de la autora de la carta que da inicio a este expediente: "Don José Galigniana, puso unas delineaciones escesibamente perjudiciales, y tan fuera de la línea topografica, que la esponente, se vio en el imprescindible caso de recursar". ${ }^{33} \mathrm{Al}$ mismo tiempo, argüía que el trabajo realizado por el agrimensor, cinco años atrás, había imposibilitado la construcción de su casa en la intersección de las calles San Juan y Ayacucho, ${ }^{44}$ ubicada en una zona urbana a pocas cuadras del centro de la ciudad previo al terremoto y también muy cerca de lo que estaba construyéndose como la "ciudad nueva". Agregaba que, luego de haber advertido el cambio de administración, había recurrido al comisario de la ciudad a quien le había presentado cómo se disponía a construir el cerco de su terreno y quien, al mismo tiempo, le había otorgado el permiso para iniciar dicha obra. Sin embargo, "con la aprobación de dicho sr dio prencipio al trabajo y cuando tiene construidas sesenta varas de cerco aparece el Sr Galigniana paralizando por segunda vez el trabajo". 45

\footnotetext{
${ }^{42}$ A.G.P.M. Sección Independiente. Registro Oficial año 1867. Pág 153-154.

${ }^{43}$ A.G.P.M. Sección Independiente. Departamento Topográfico. Carpeta 34. Documento n`55. Foja ${ }^{\circ} 1$.

${ }^{44}$ La manzana en la que se encontraba el terreno de Doña Enriqueta Zuloaga está marcada con un círculo rojo en el plano que se encuentra en la próxima página con el fin de dar cuenta de su posición cercana tanto al antiguo centro de la Ciudad como el que emergió luego del terremoto de 1861.

${ }^{45}$ A.G.P.M. Sección Independiente. Departamento Topográfico. Carpeta 34. Documento n55. Foja ${ }^{\circ} 1$.
} 
Imagen 1: Plano de la ciudad de Mendoza, 1872

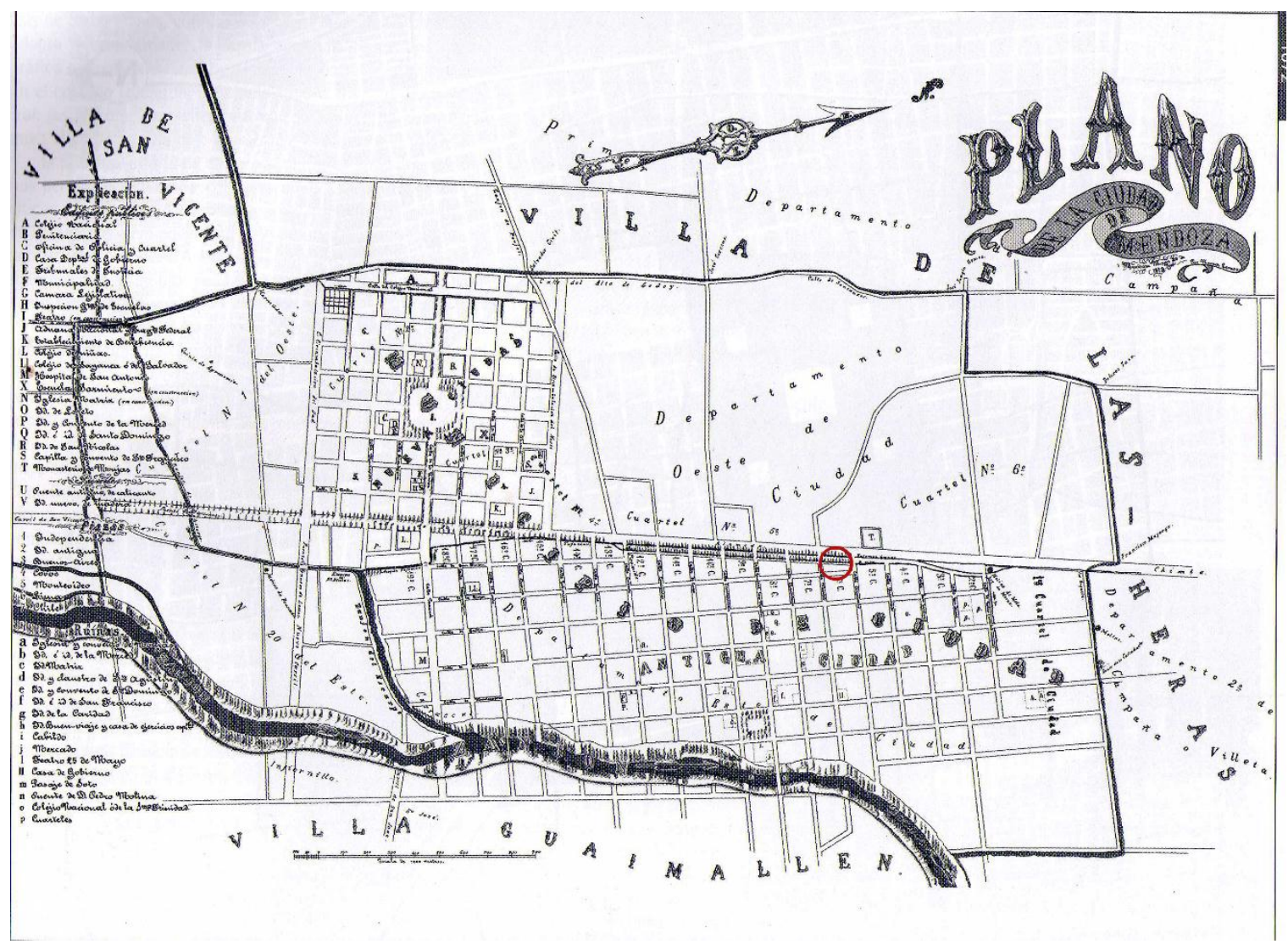

Fuente: Plano de la ciudad de Mendoza confeccionado por Numa Lemos, recuperado de: Jorge Ricardo Ponte, Mendoza aquella ciudad de barro: historia de una Ciudad andina desde el siglo XVI hasta nuestros días, (Mendoza: CONICET, 1987), 224.

En lo que puede considerarse un segundo momento de la carta enviada al gobernador, Enriqueta se dispuso no solo a denunciar que "muchas somos el juguete y menoscabo del Sr. Galigniana", 46 sino que, incluso, cuestionó las delineaciones que el jefe del Departamento Topográfico había realizado a sus vecinos y vecinas -Señor Barcala, Doña Manuela Tello y al Señor Aguilar- argumentando que éstas no habían sido equitativas puesto que actuaba "quitándole a unos para darle a otros". ${ }^{47}$ Finalmente, se despedía agregando que, de ser necesario, ella podía aportar como testigos a muchos residentes del barrio con tal de probar su verdad.

Veinte días más tarde, desde la oficina de gobierno, se decide que se le dé pase del expediente al agrimensor de la ciudad para que éste realice su informe. Pero más que esto, lo

\footnotetext{
${ }^{46}$ A.G.P.M. Sección Independiente. Departamento Topográfico. Carpeta 34. Documento n55. Foja ${ }^{\circ} 1$.

${ }^{47}$ A.G.P.M. Sección Indepentiente. Departamento Topográfico. Carpeta 34. Documento n55. Foja ${ }^{\circ} 1-2$.
} 
que realiza Galigniana es un descargo en calidad de defensa de su proceder y una denuncia a la señora Zuloaga en tanto declaraba que "todo el relato del presente escrito es un compendio de embustes y sandeces forzadas para encubrir la notoria malicia con que ha prosedido". ${ }^{48}$ Por otro lado, agregaba que todo lo realizado por él se ajustaba a lo establecido por la ley vigente y que Enriqueta no solo no había respetado lo que esta establecía sino que sus acciones estaban signadas por la especulación ya que aprovechó el contexto de "la época de motin de los presidiarios y ladrones [para consultar] solo su particular interés con visible trastorno de la delineación ya establecida, y en disonancia con los edificios patentados a derecha e isquierda de su local como esta de manifiesto y con toda desverguensa impuesta" 49

Lo cierto es que, en su escrito, Galigniana reforzó la moción que aceptaba que los sujetos idóneos para expedirse en este tipo de asuntos eran justamente los agrimensores ya que eran ellos quienes contaban no solo con la expertise, sino con la autorización oficial para actuar. Este argumento cobra importancia cuando enuncia que la ciudadana no puede probar ninguna de las cuestiones que afirma, "pues el solo echo de poner travajo en tal tiempo prueba su maldad, que llendo apollarse en el comisario que no tiene facultad para tales concesiones y si orden superior para cuidar que nadie ponga travajo sin obtener el voleto de constancia de ser en la línea dada y marcada por el agrimensor con arreglo a la lei de la materia". ${ }^{50}$

Para resolver este conflicto, Melitón Arroyo, gobernador de Mendoza, y Francisco Civit, ministro de gobierno, acordaron con la iniciativa de Adriano Gómez -juez que se expidió en la causa- que se tratara de apelar a la figura de Julio Balloffet, reconocido ingeniero y agrimensor francés que lideró múltiples tareas en la provincia, entre ellas, la reconstrucción de la ciudad luego del terremoto de 1861. En ese sentido, se le solicitó un informe de la situación, pedido que contó con el aval de la denunciante.

Entre el 11 y el 23 de mayo de 1867 Balloffet cumplió con el encargo y en pocas palabras dictaminó que "de ningún modo puede quedar la nueva pared de adobe establecida", 51 ya que entendía que la construcción no respeta la línea que ya había sido aprobada. De esta manera, Balloffet respaldaba lo establecido y, luego reforzado, por su colega Galigniana. Finalmente, el juez Gómez se hizo eco de lo expuesto por Ballofet y, especialmente, por José Galigniana, en tanto se refirió a él en su dictamen: "estese a la delineación practicada por el Gefe del Departamento Topográfico" ${ }^{„ 52}$ y, junto con la

\footnotetext{
${ }^{48}$ A.G.P.M. Sección Indepentiente. Departamento Topográfico. Carpeta 34. Documento n ${ }^{\circ 55}$. Foja n ${ }^{\circ} 3-4$.

${ }^{49}$ A.G.P.M. Sección Indepentiente. Departamento Topográfico. Carpeta 34. Documento n55. Foja n ${ }^{\circ} 4$.

${ }^{50}$ A.G.P.M. Sección Indepentiente. Departamento Topográfico. Carpeta 34. Documento n ${ }^{\circ} 55$. Foja ${ }^{\circ} 4$.

${ }^{51}$ A.G.P.M. Sección Independiente. Departamento Topográfico. Carpeta 34. Documento n55. Foja n ${ }^{\circ} 5$.

${ }^{52}$ A.G.P.M. Sección Independiente. Departamento Topográfico. Carpeta 34. Documento n55. Foja $n^{\circ} 6$.
} 
notificación realizada por parte del escribano de la provincia-a Enriqueta Zuloaga, se dio por finalizado el problema.

Conforme a lo expuesto, es posible advertir que efectivamente una multiplicidad de sujetos participó en la resolución del conflicto, la mayoría de ellos agentes del Estado provincial. En relación a las premisas del apartado anterior, la apelación a un saber especializado parece haber sido un argumento suficiente para sostener una posición tomada con antelación vinculada a ese campo de conocimiento. De hecho, los dos agrimensores que figuran en este documento son dos sujetos que contaron con una trayectoria reconocida en la provincia, la cual se sustentaba en su obra y en los cargos públicos que ocuparon a lo largo de ella. Por un lado, Galigniana no solo había sido en reiteradas ocasiones Jefe/Director del Departamento Topográfico, incluso en sus comienzos, sino que fue uno de los primeros agrimensores de número reconocidos por el Estado provincial $^{53} \mathrm{y}$, por el otro, Julio Balloffet, tal vez el agrimensor más distinguido por haber llevado a cabo la empresa de la reconstrucción de la ciudad junto con otras tareas de mensura e ingenieriles en el departamento de San Rafael, ubicado al sur de la provincia. De hecho, con posterioridad al hecho que aquí se analiza, ocupó el mismo cargo que su colega en la década de 1870 y 1880.

Por otro lado, conviene resaltar que el proceso tuvo una duración de no más de dos meses, en un contexto signado por la inestabilidad política. Al mismo tiempo, entre los agentes estatales que participaron en él es posible reconocer que no existió, al menos en ese corto período, un recambio entre las autoridades. De esta manera, también podemos pensar que la celeridad con la que se dio fin al reclamo de la vecina pudo haber tenido que ver o bien con la posición social de la señora Zuloaga, la cual podría haberle conferido un tratamiento especial, o bien con que se trataba de un procedimiento recurrente, cuestión en la que será importante seguir indagando en futuros trabajos.

Por último, es importante destacar que ante la denuncia de un comisario que se excedió en sus funciones y en el marco de la organización del Estado provincial, al menos en los documentos visitados hasta la fecha, no aparece ningún tipo de sumario u otro tipo de proceso que tuviera como fin condenar ese accionar. También, durante ese período, si era una práctica habitual aquella que habilitaba a que jueces menores actuaran en materia de deslinde de terrenos y acciones similares. ${ }^{54}$

\section{El caso de Enriqueta: ¿una excepción a la norma?}

\footnotetext{
${ }^{53}$ Molina, “Agrimensores, gobierno y derecho", 11-13.

${ }^{54}$ Molina, "Agrimensores, gobierno y derecho".
} 
Una lectura contextualizada del caso recién expuesto respecto de otros documentos, permitió reconocer que el reclamo de Zuloaga no fue el único iniciado y presentado a las autoridades provinciales en esos años. En enero de 1864, un vecino de la ciudad llamado Julio Regulus, le reclamaba al gobernador los daños económicos que estaba sufriendo porque le habían notificado desde la comisión topográfica que la construcción que había realizado no estaba conforme a la norma. En esa carta, mencionaba que José Galigniana había aprobado la construcción y era el mismo Galigniana quien impedía que se concluyeran los trabajos. Al mismo tiempo, Regulus solicitaba que "se me indecmise el trabajo echo (...) porque la regla del director dice quel que ase el mal lo paga". ${ }^{5}$

Un caso similar es el que se presentó en 1866 mediante un reclamo realizado por el apoderado de un vecino de la villa de Maipú, Luis Gatica, ante el gobernador. En el comunicado se mencionaba que su representado, Francisco Monasterio, había sido perjudicado por la expropiación "de terrenos por la apertura de la calle Ozamis"56 por el trabajo realizado por el "agrimensor de siudad". ${ }^{57}$ Monasterio presentaba al finalizar esa carta el valor de las tierras expropiadas y le solicitaba al gobernador "se sirva mandárseme dicho valor por la caja provincial". 58

Lo cierto es que luego del terremoto de 1861, los esfuerzos por establecer criterios claros en el ordenamiento del territorio y en la regulación de las construcciones en la "ciudad nueva" están presentes en la correspondencia que mantuvieron el gobernador y el ministro de gobierno con los agrimensores del Departamento Topográfico. ${ }^{59}$ Particularmente, en octubre del año 1862 el gobernador de la provincia, Franklin Villanueva, en una carta al Jefe del Departamento Topográfico mencionaba que "en la delineación del terreno que debe ocupar la nueva ciudad se atiende al croquis formado por el coronel Gerónimo Espejo, el cual presenta como más ventajas para la salubridad que las calles den frente, no a los cuatro puntos cardinales sino a medio viento (...) lo que usted tendrá presente para la mensura y ordenamiento del terreno". ${ }^{60}$ Buscaba, de cierta manera, estandarizar lo relativo a las construcciones tomando una postura preventiva a partir de los sucesos del año anterior.

Un antecedente importante es que el 26 de noviembre de 1862 José Galigniana recibió una carta de autoridades superiores que establecía cuales debían ser los pasos a seguir si los

\footnotetext{
55 A.G.P.M. Sección Independiente. Departamento Topográfico. Carpeta 34. Documento n ${ }^{\circ}$ 49b. Foja ${ }^{\circ} 1$.

${ }^{56}$ A.G.P.M. Sección Independiente. Departamento Topográfico. Carpeta 34. Documento n54. Foja ${ }^{\circ} 3$.

${ }^{57}$ A.G.P.M. Sección Independiente. Departamento Topográfico. Carpeta 34. Documento n54. Foja n ${ }^{\circ} 3$.

${ }^{58}$ A.G.P.M. Sección Independiente. Departamento Topográfico. Carpeta 34. Documento n54. Foja n ${ }^{\circ} 3$.

${ }^{59}$ A.G.P.M. Sección Independiente. Departamento Topográfico. Carpeta 34. Documento n`48, n`50 y n`52.

${ }^{60}$ A.G.P.M. Sección Independiente. Departamento Topográfico. Carpeta 34. Documento n48. Foja ${ }^{\circ} 2$.
} 
trabajos realizados por los agrimensores afectaban las propiedades particulares de los vecinos. Asumiendo la posibilidad de que "las delineaciones, rectificaciones y enanche o apertura de calles que se están practicando (...) ocasiona desagrados y controversias entre el agrimensor y algunos interesados propietarios", 61 establecía que el agrimensor debía "levantar un pequeño plano de la superficie ocupada anotando al pie el número de varas que resulten y el valor estimado sin perjuicio de continuar los trabajos". ${ }^{2}$ Luego, sería la legislatura la encargada de aprobar los medios efectivizar esas indemnizaciones.

De esta manera, con anterioridad a la presentación de los reclamos presentados, se había habilitado una suerte de canal para vehiculizar los reclamos de propietarios junto con mecanismos para saldar los perjuicios que pudieran haber ocasionado el accionar de los agrimensores, pero, especialmente, se establecía la superioridad de los trabajos diseñados por el Departamento Topográfico respecto de intereses particulares afectados. Así como lo planteó Eugenia Molina, "la acción del gobierno se habría apoyado en modalidades político administrativas en las que la voluntad ejecutiva trató de desplazar prácticas jurisdiccionales que reconocían la opinión y derechos de los vecinos gestionados con discursos y en escenarios judiciales". ${ }^{63}$ Esto último podría pensarse entonces como un indicio de la transición de un paradigma jurisdiccional hacia un paradigma administrativo en tanto que priorizaba la conservación del orden público en detrimento de la atención a reclamos que pudieran haber estado vinculados con la conservación de un estado de las cosas anterior. ${ }^{64}$

\section{Consideraciones finales y posibles interrogantes para futuras investigaciones}

Este trabajo propuso una primera aproximación al conocimiento del rol del Departamento Topográfico y los agrimensores que lo componían en el gobierno del territorio local y a la relación que éste tenía con los vecinos/as y con otros agentes y agencias del Estado provincial a partir de una serie de documentos que pasaron en el año 1867 por esa oficina y por las manos de quienes trabajan en ella y de otros agentes estatales que, desde sus roles y sapiencias, tuvieran injerencia en lo que éstos establecían, cuestionaban, proponían.

Fue por ello que, en primer lugar, se recurrió a una contextualización de la realidad

\footnotetext{
${ }^{61}$ A.G.P.M. Sección Independiente. Departamento Topográfico. Carpeta 34. Documento n ${ }^{\circ} 48$. Foja ${ }^{\circ} 6$.

${ }^{6}$ A.G.P.M. Sección Independiente. Departamento Topográfico. Carpeta 34. Documento n ${ }^{\circ} 48$. Foja n ${ }^{\circ} 6$.

${ }^{63}$ Eugenia Molina, Saberes, territorio y estatalidad: Departamento Topográfico y agrimensores en Mendoza, 1850- 1860". Avances del Cesor, 17 (23), 2020,

${ }^{64}$ Alejandro Agüero, "Las categorías básicas de la cultura jurisdiccional". En De justicia de jueces a justicia de leyes: Hacia la España de 1870”. Coordinado por Marta Lorente. (Madrid: Consejo General del Poder Judicial, 2007).
} 
histórica de Mendoza en ese año con el fin de ubicar el peso simbólico y material que significaba el Departamento Topográfico dentro del organigrama de la hasta entonces inestable administración local. Si bien los recursos y los proyectos dedicados a esta oficina fueron bien escasos, es importante destacar que desde el poder ejecutivo se pensaron no poco ambiciosos planes que rondaron la órbita del Departamento. Caso emblemático es la comisión de un plano topográfico del oasis más grande de la provincia a Julio Balloffet quien, a pesar de no formar parte en ese año del elenco de agrimensores a sueldo del Departamento Topográfico, se movió en ese campo y su labor estuvo estrechamente vinculada a las funciones que debía cumplir esa oficina.

Por otro lado, el estudio del conflicto presentado por la ciudadana Enriqueta Zuloaga por medio de una carta dirigida al gobernador de la provincia nos estimula en la formulación de una serie de hipótesis que resultan interesantes para compartir y, en las que seguramente, será necesario seguir pensando. Una de las cuestiones a destacar es la celeridad con la que se resolvió el caso, más aún, teniendo en cuenta el agitado contexto de inestabilidad política reflejada en la rebelión colorada del año anterior, una serie de motines a las que se hace referencia en el expediente, entre otras. Una hipótesis que surge de este trabajo y que se pretende seguir profundizando es aquella que afirma que esto último podría significar que, a pesar de esos embates políticos regulares, en la administración local se contaba con una serie de procedimientos aceitados que seguían su curso sin verse alterados por las coyunturas políticas y que, al mismo tiempo, podía incluso habilitar que los elencos que formaban oficinas estatales vinculadas a un saber técnico permanecieran inamovibles a pesar de la agitación política.

Sin embargo, tal vez la nota más sustancial que se presenta en este documento es que, a pesar de haber contado con un juez en la causa y que la misma denunciante haya ofrecido aportar una serie de testimonios que reafirmen su posición, no solo no se dio lugar a una investigación de tipo sumaria, sino que aparentemente fue suficiente contar con la voz de un experto (Ballofett) que convalidara lo que su colega (Galigniana) había realizado para no dar lugar a la denuncia de Zuloaga respecto del supuesto mal obrar del jefe del Departamento. Siguiendo esa línea, por un lado, evidencia que se está ante un caso en el que el saber especializado, es decir la agrimensura, podría haber funcionado como principio legitimador de la práctica y, por otro, a una posible respuesta de tipo corporativa ante la acusación y reclamo de una vecina. En ese sentido, el impacto del terremoto de 1861 en la necesidad de contar con una serie de criterios sustentados en un saber técnico respecto de las construcciones de viviendas, delineaciones de calles y caminos es una cuestión en la que debemos seguir 
indagando.

Por último, el estudio de caso aquí presentado no parece haber representado una excepción a la norma sino la confirmación de una tendencia que desde el mismo poder ejecutivo provincial se había diseñado. Al contextualizar el reclamo de Enriqueta Zuloaga en el conjunto de documentos correspondientes a la década de 1860, es posible advertir, por un lado, una fuerte tendencia a la burocratización en la resolución de conflictos que afectaran las propiedades particulares y, por el otro, que desde ese Estado que estaba configurándose habían comenzado a crearse una serie de dinámicas que pusieran por encima de posibles reclamos o cuestionamientos la pervivencia del orden público.

Lo cierto es que, al ser una primera aproximación y no un trabajo de síntesis, difícil es arribar a conclusiones cerradas y lo que sucede es que emergen nuevos interrogantes y nuevas líneas de investigaciones que se espera puedan ir encontrando lugar en próximos trabajos. Algunas de ellas ya han sido adelantadas, otras tienen que ver con la reconstrucción de las trayectorias de los agrimensores junto con el modo en que fueron especializando su saber y cómo ese saber fue reconocido como legítimo y, en ese sentido, si habrá o no necesario contar con una red de colegas u otros agentes estatales que, ante cuestionamientos de la población, convalidaran su accionar. 